\title{
A possible trade-off between clean air and clean water
}

\author{
Douglas R. Smith, Marie Stephensen, Kevin W. King, Helen P. Jarvie, Rick Haney, and Mark R. Williams
}

$\mathrm{T}$ he recent public focus on Lake Erie harmful algal blooms (HABs) has pushed researchers, conservationists, and policy makers to attempt to isolate the cause(s) and the solution(s) to this problem. Previous reports indicated as many as 25 potential "causes" of the HABs (Smith et al. 2015c). More recently, researchers have placed further scrutiny on individual causes, such as tile drainage (King et al. 2015), fertilizer placement (Smith et al. 2016), fertility recommendations (Smith et al. 2018), or groups of these potential causes (Smith et al. 2015a; Jarvie et al. 2017; King et al. 2017; Smith et al. 2017; Williams et al. 2017).

One item that has yet to be addressed from the original list of causes is the influence of decreased sulfate $\left(\mathrm{SO}_{4}\right)$ concentrations in rainfall and a concomitant increase in rainfall and soil $\mathrm{pH}$ (Smith et al. 2015c). Acid rain that resulted from power plant and other emissions was known to degrade aquatic and soil quality and damage structures in the 1970s and 1980s (Seaborn 1982; Helvey et al. 1982).

The 1990 Amendments to the Clean Air Act was enacted to address, among other things, acid rain (40 CFR C.50-97). Thus, flue-gas desulfurization has been adopted by power plants to decrease sulfur (S) emissions from power plants. Figure 1 shows the rainfall chemistry at one of the National Atmospheric Deposition Program's sites nearest the Western Lake Erie Basin (WLEB). There have been

Douglas R. Smith and Rick Haney are a soil scientists with the USDA Agricultural Research Service (ARS) Grassland, Soil, and Water Research Laboratory in Temple, Texas. Marie Stephensen is a graduate research assistant at Baylor University and former undergraduate research chemistry student from the University of Mary Hardin Baylor. Kevin W. King is an agricultural engineer at the USDA ARS Soil Drainage Unit in Columbus, Ohio. Helen P. Jarvie is a principal scientist and hydrochemist at the Centre for Ecology and Hydrology in Wallingford, United Kingdom. Mark W. Williams is a research agricultural engineer with the National Soil Erosion Research Laboratory in West Lafayette, Indiana. marked decreases in the concentration of $\mathrm{SO}_{4}$ and nitrate $\left(\mathrm{NO}_{3}\right)$ in rainfall, while the rainfall $\mathrm{pH}$ has increased. Similar results have been seen throughout the United States as well as worldwide upon the passage of regulations to control acid rain (Kahl et al. 2004; Sopauskiene and Jacineviciene 2006; Strock et al. 2014).

Total phosphorus (TP) has increased in rivers and lakes that are not impacted by anthropogenic inputs (e.g., fertilizers or wastewater) over the last 20 years in both North America and Europe (Kopacek et al 2015; Stoddard et al. 2016). In the WLEB, tributary TP loads have remained nearly stable since the early 2000s; however, soluble P (SP) loads have increased over this period (Joose and Baker 2011; Jarvie et al. 2017). Unfortunately, the studies of pristine systems did not include differentiation between SP and TP to determine if the soluble or particulate fraction was contributing to the increased P loading (Kopacek et al. 2015; Stoddard et al. 2016). In the WLEB, the increase in SP loading has been closely associated with the extent of HABs; however, increased SP loading is masked by the high TP loads when trend analysis is completed for TP during the last two decades.

The large-scale trends in precipitation chemistry over the last 20 years have been directly linked to changes in soil chemistry and water quality. For example, increasing organic matter solubility and enhanced export of dissolved organic carbon (DOC) have been documented in acid-sensitive watersheds across North America and northern Europe (Monteith et al. 2007). However, it is not yet known whether the observed continental-scale increases in freshwater TP concentrations could be linked to changes in precipitation chemistry.

Upon compilation of these disparate data sources, some interesting gaps in our knowledge are highlighted. Chiefly among these are the following:

1. Does a link exist between changes in precipitation chemistry and altered $\mathrm{P}$ loss trends in the last 20 years?
2. If $\mathrm{P}$ losses are affected by precipitation chemistry, what $\mathrm{P}$ fractions would be impacted?

3. If $\mathrm{P}$ loss is increased in either pristine or anthropogenically managed systems as a function of altered rainfall chemistry, what mitigation strategies might be used?

Since SP losses in the WLEB have occurred concomitantly with changes to precipitation chemistry, we conducted a preliminary study to determine if there could be a relationship between the two. Soils and fertilizers were chosen for this study, as the instantaneous interactions between rainwater and these two P sources are likely to have the greatest impact on changes to P loss from fields and watersheds.

\section{PROCEDURES}

Precipitation chemistry measured by the National Atmospheric Deposition Program at Huntington, Indiana, was used as the basis for this work. Rainwater in 1990 had a mean $\mathrm{pH}$ of 4.4, and $\mathrm{SO}_{4}$, $\mathrm{NO}_{3}$, and ammonium $\left(\mathrm{NH}_{4}\right)$ concentrations of 2.5, 1.7, and $0.35 \mathrm{mg} \mathrm{L}^{-1}(2.5$, 1.7 , and $0.35 \mathrm{ppm}$ ), respectively. In 2011, mean rainwater $\mathrm{pH}$ was 5.1 , while $\mathrm{SO}_{4}$, $\mathrm{NO}_{3}$ and $\mathrm{NH}_{4}$ concentrations were 1.05, 1.0 and $0.45 \mathrm{mg} \mathrm{L}^{-1}(1.05,1.0$, and 0.45 $\mathrm{ppm})$, respectively. Precipitation chemistry was simulated by mixing $20 \mathrm{~L}$ (5.3 gal) of deionized water with these constituents, henceforth called 1990 precipitation and 2011 precipitation.

Soils from the WLEB were collected from two sites in Indiana (IN1 and IN2) and four sites in Ohio $(\mathrm{OH} 1, \mathrm{OH} 2$, $\mathrm{OH} 3$, and $\mathrm{OH} 4)$, dried at $60^{\circ} \mathrm{C}\left(140^{\circ} \mathrm{F}\right)$, ground, and sieved to pass a $2 \mathrm{~mm}(0.08$ in) mesh sieve. Triplicate samples of each soil were extracted with 1990 precipitation and 2011 precipitation, using a 1:10 soil to extractant ratio. After 5 minutes of shaking at 200 oscillations $\mathrm{min}^{-1}$, samples were centrifuged at $5,000 \times$ gravity, and the supernatant was filtered $(0.45 \mu \mathrm{m})$ and acidified. In addition to the soils, six fertilizers (bone meal, rock phosphate, 


\section{Table 1}

Phosphorus, aluminum, calcium, and iron concentrations in extractions for two soils from Indiana and four soils from Ohio with simulated rainfall from 1990 and 2011.

\begin{tabular}{|c|c|c|c|c|c|c|c|c|c|c|c|c|}
\hline \multirow[b]{2}{*}{ Soil } & \multicolumn{3}{|c|}{ Phosphorus (mg L-1) } & \multicolumn{3}{|c|}{ Aluminum (mg L-1) } & \multicolumn{3}{|c|}{ Calcium (mg L-1) } & \multicolumn{3}{|c|}{ Iron $\left(\mathrm{mg} \mathrm{L}^{-1}\right)$} \\
\hline & 1990 & 2011 & $p$ & 1990 & 2011 & $p$ & 1990 & 2011 & p & 1990 & 2011 & $p$ \\
\hline IN1 & 0.17 & 0.29 & $\star *$ & 0.07 & 0.16 & $* * *$ & 82.90 & 79.30 & & 0.256 & 0.453 & * \\
\hline IN2 & 0.95 & 1.12 & $\dagger$ & 3.44 & 3.92 & & 14.60 & 14.20 & & 4.04 & 3.37 & \\
\hline $\mathrm{OH} 1$ & 3.25 & 3.18 & & 1.10 & 1.20 & & 21.60 & 19.70 & $\dagger$ & 1.51 & 1.26 & $\dagger$ \\
\hline $\mathrm{OH} 2$ & 0.31 & 0.36 & & 1.27 & 1.22 & & 22.80 & 21.40 & & 1.88 & 1.64 & \\
\hline $\mathrm{OH} 3$ & 0.28 & 1.36 & $* *$ & 2.81 & 3.22 & * & 9.28 & 9.28 & & 6.01 & 3.93 & * \\
\hline $\mathrm{OH} 4$ & 3.25 & 2.99 & * & 3.08 & 1.25 & * & 19.30 & 18.60 & & 3.09 & 1.52 & \\
\hline
\end{tabular}

Notes: Significant differences exist between rainfall chemistry treatments for a given soil and element when there is an annotation in the $p$ column. Significance occurs at $p<0.05(*), p<0.01(* *)$, or $p<0.001(* * *)$.

† Represents a $p$-value between 0.05 and 0.15 .

single superphosphate [SSP], triple superphosphate [TSP], diammonium phosphate [DAP], and monoammonium phosphate [MAP]) were also extracted with 1990 precipitation and 2011 precipitation. This was completed using the same procedures as the soils, except a 1:100 fertilizer to extractant ratio was used.

Soluble P was measured on a Sans++ segmented flow analyzer (Skalar, Inc., Buford, Georgia), while aluminum (Al), calcium $(\mathrm{Ca})$, and iron $(\mathrm{Fe})$ were analyzed on a Vista-MPX ICP (Varian, Palo Alto, California) on the filtered, acidified samples. Statistics were performed in JMP v. 10.0.0 (SAS Institute, Cary, North Carolina), using $t$-tests to compare means of precipitation treatments by soil or fertilizer. Further, $\mathrm{P}$ concentrations for each soil were regressed against cation (Al, $\mathrm{Ca}$, or $\mathrm{Fe}$ ) concentrations for each soil to determine the significance of any relationships that might exist.

\section{RESULTS}

Across the six soils used in the current study, SP increased, on average, by 0.16 $\mathrm{mg} \mathrm{L^{-1 }}(0.16 \mathrm{ppm})$ when they were extracted with the 2011 precipitation compared to the 1990 precipitation (table 1). An increase in SP was observed for four of the six soils when using the 2011 precipitation, with the largest increase (1.08 $\mathrm{mg} \mathrm{L}^{-1}$ [1.08 ppm]) occurring in the OH3 soil. The 2011 precipitation also extracted more $\mathrm{Al}$ in four of the six soils compared to the 1990 precipitation (table 1). In contrast, $\mathrm{Ca}$ and $\mathrm{Fe}$

\section{Figure 1}

Mean annual sulfate ( $\mathrm{SO}$ ), nitrate (NO), and $\mathrm{pH}$ in rainfall at the National Atmospheric Deposition Program (NADP) site IN20 from 1983 to 2016. (Original data source is the NADP, site IN20, Roush Lake near Huntsville, Indiana: http:// nadp.sws.uiuc.edu/.)

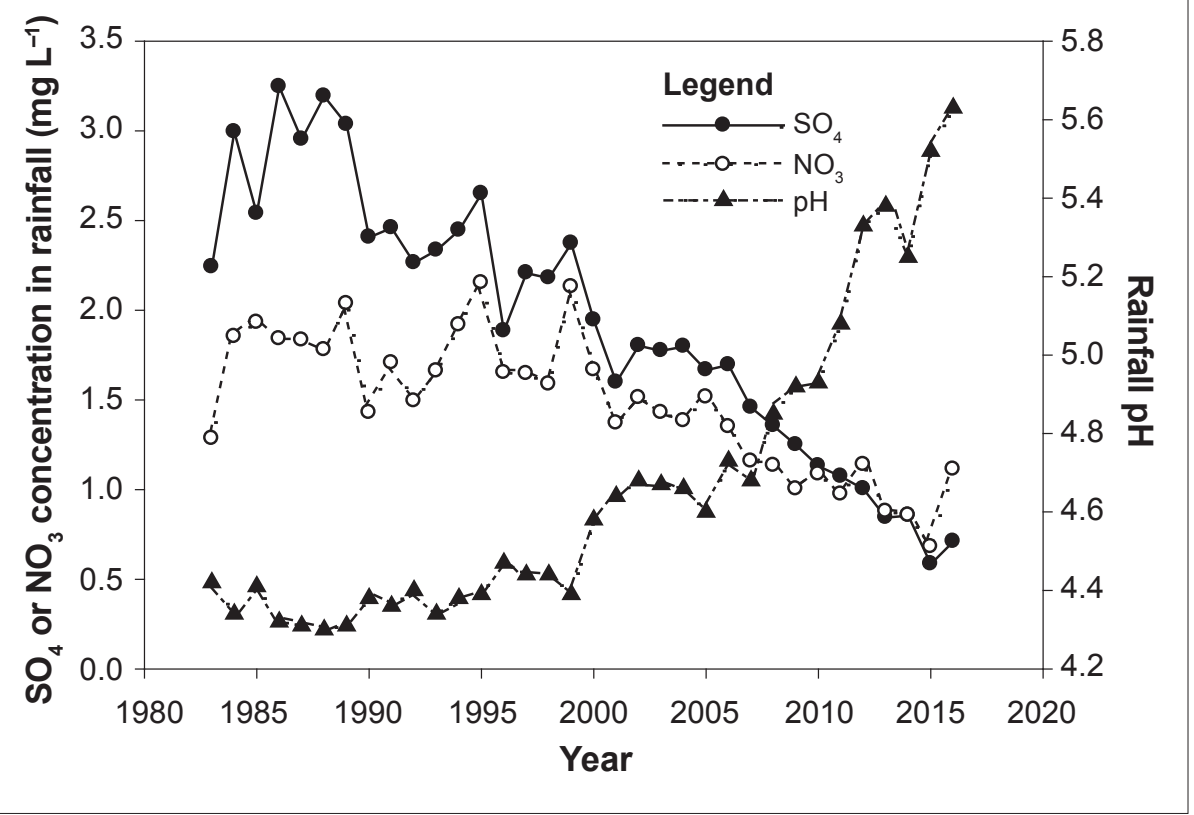

decreased with the 2011 precipitation in six and five soils, respectively.

Significant positive correlations were observed between extracted $\mathrm{P}$ and $\mathrm{Al}$ in two of the six soils studied (IN1 and $\mathrm{OH} 4$ ). Figure 2 shows the relationship between $\mathrm{P}$ and $\mathrm{Al}$ for $\mathrm{OH} 4$. These trends were not observed in every soil, but could be one mechanism for increase SP loss from some soils. Further study is needed to determine if other soils exhibit similar relationships, and what characteristics those soils have in common. Two soils were found to have significant correlations between extractable $\mathrm{Fe}$ and $\mathrm{P}$, whereas there were no significant correlations observed between extracted $\mathrm{P}$ and $\mathrm{Ca}$.

In four of the six fertilizers studied, 2011 precipitation resulted in greater SP concentrations compared to 1990 precipitation (figure 3). Only rock phosphate showed significantly lower SP concentrations when extracted with 2011 precipitation. The most commonly used fertilizer sources in the WLEB (MAP and DAP) both showed that $\mathrm{P}$ loss from direct contact with pre- 


\section{Figure 2}

Relationship between soluble phosphorus (SP) and aluminum (Al) from soil $\mathrm{OH}_{4}$.

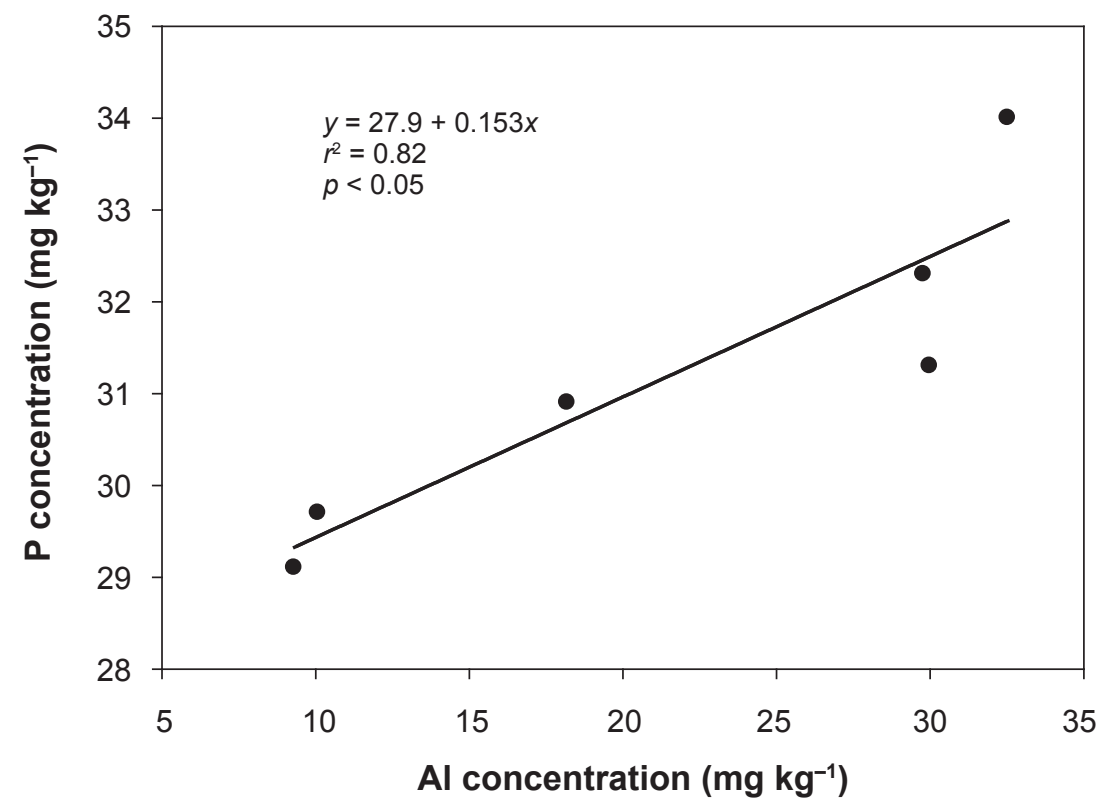

\section{Figure 3}

Soluble $\mathrm{P}(\mathrm{SP})$ concentrations for fertilizers upon extraction with simulated precipitation from 1990 and 2011. Bars within a fertilizer treatment with different letters indicate a significant treatment effect of rainwater chemistry.

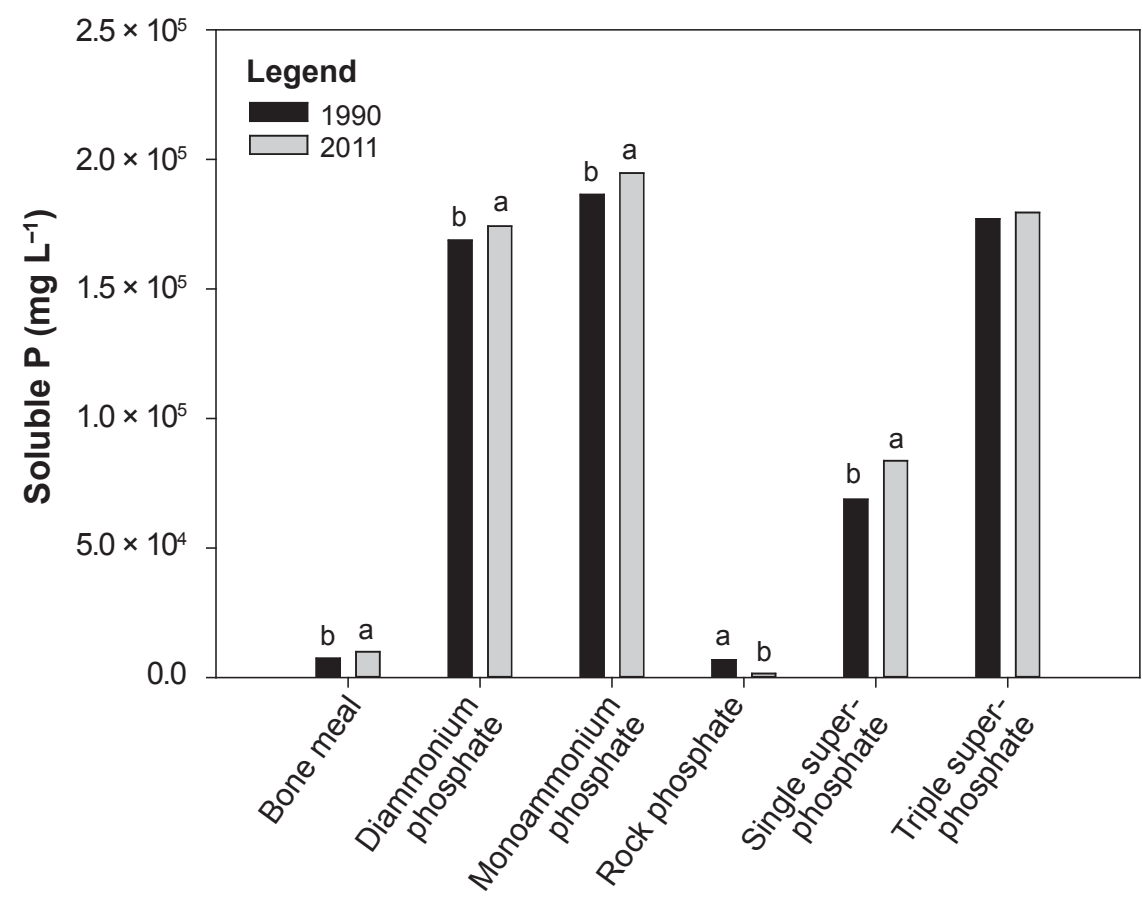

Fertilizer cipitation may have increased during the period from 1990 to 2011.

\section{IMPLICATIONS}

Data presented herein are preliminary results from a study designed to determine if precipitation chemistry could be a contributing factor to the increased SP loadings to Lake Erie, among a wider range of potential drivers (Smith et al. 2015c). These other drivers include increasing extent and intensity of tile drainage in the WLEB, which enhances the hydrologic connectivity between $\mathrm{P}$ sources (i.e., agricultural fields) and receiving waters (King et al. 2015; Smith et al. 2015b); and role of conservation practices, such as no-till and grassed waterways, that reduce TP while increasing SP losses (Smith et al. 2015a). Based on our preliminary results, we cannot rule out the possibility that anthropogenically induced declines in $\mathrm{SO}_{4}$ and the associated $\mathrm{pH}$ increase in precipitation between 1990 and 2011 may have resulted in greater SP loss from soils and fertilizers. However, this dataset alone is insufficient to confirm that this has occurred, and further studies are underway to develop and extend this pilot study.

From 2000 to 2014, continental scale TP loadings to water bodies in the United States increased at a rate of approximately

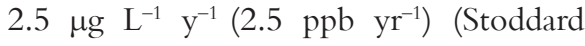
et al. 2016), but with no corresponding assessment of speciation of TP as soluble or particulate concentrations. Changes in atmospheric deposition offer a plausible explanation for such widespread increases in TP concentrations, which could also elucidate why these changes are occurring in pristine watersheds. Atmospheric deposition may have a direct impact through increased TP deposition linked to particle deposition of atmospheric dust (which may increase particulate $\mathrm{P}$ in runoff). Alternatively, as shown in this pilot study, it may have an indirect impact, as a result of decreased $\mathrm{SO}_{4}$ deposition and/ or increased rainfall $\mathrm{pH}$ (driving increased SP losses).

Mitigation of acid rain deposition in the United Kingdom resulted in increased DOC concentrations in streams and rivers (Evans et al. 2005). Decreased S deposition in Sweden decreased in-stream 
$\mathrm{SO}_{4}$ concentrations with increased total organic $\mathrm{C}$ and $\mathrm{Cl}$ stream concentrations (Folster and Wilander 2002). While P was not measured in their study, it is not out of the realm of possibility that other anions increase when $\mathrm{SO}_{4}$ concentrations decrease. From the 1980s to the late 2000s, as Adirondack streams recovered from wet deposition of $\mathrm{S}$, streams' water $\mathrm{SO}_{4}$ concentrations declined while DOC concentrations increased (Lawrence et al. 2011). Declining wet acid deposition and land disturbance resulted in greater DOC and $\mathrm{Fe}$ concentrations in $\mathrm{UK}$ streams (Neal et al. 2008).

An evaluation of Dutch moorland pools demonstrated that during recovery from acid rain deposition, SP and DOC concentrations increased while TP concentrations decreased (van Kleef et al. 2010). In this study, they further observed that pool water $\mathrm{pH}$ was directly related to SP concentration and that SP concentrations increase as a result of increased organic matter decomposition. Recovery from acid rain deposition resulted in improved macroinvertebrate and diatom species richness in the streams and lakes of the United Kingdom. (Tipping et al. 2002). Increased drinking water reservoir DOC concentrations have been observed to occur concomitantly with declining acid deposition (Oulehle and Hruska 2009).

Soil DOC concentrations have been shown to increase in response to declining acid deposition from rainfall and increased microbial activity (Vanguelova et al. 2010). Increased acid deposition to soils resulted in lower soil $\mathrm{pH}$ and in turn increased Al in soil solution (Stevens et al. 2009). They also found soil $\mathrm{pH}$ was positively correlated with $\mathrm{Ca}$ and negatively correlated with $\mathrm{Fe}$ (Stevens et al. 2009). European air emission standards resulted in declining soil $\mathrm{SO}_{4}$ concentrations in most Swedish forest sites; however, soil $\mathrm{pH}$ and $\mathrm{Al}$ concentrations recovered from acidification at some, but not all sites (Karlsson et al. 2011).

Applications of $\mathrm{S}$ to alfalfa (Medicago sativa L.) and corn (Zea mays L.) have been shown to decrease P uptake (Caldwell et al. 1969). In legume crops, $\mathrm{S}$ additions tended to decrease foliar $\mathrm{P}$ concentrations, whereas $\mathrm{P}$ additions tended to result in decreased foliar $\mathrm{S}$ concentrations (Jones et al. 1970). Berger et al. (2016) demonstrated that as beech (Fagis sylvatica) trees in Austria recovered from acid rain deposition, there was still substantial S in soils. However, while the soils were in the process of recovering, as evidenced by greater organic mineralization rates, high soil S concentrations resulted in low $\mathrm{P}$ uptake. In the WLEB, crop consultants and farmers have observed fewer crop P deficiencies and more crop $\mathrm{S}$ deficiencies over the last 10 to 15 years (Joe Nester, personal communication, April 26, 2017).

In the WLEB tributaries, SP loadings increased since the early 2000s with no corresponding increase in particulate $\mathrm{P}$ loadings. Our results highlight the need for more intensive and broader studies to evaluate the impacts of changing precipitation chemistry on SP losses, through benchtop and field scale studies, and to assess if this mechanism could be plausible. If so, this could present a potentially intractable trade-off between clean air and clean water: whereby improvements in air quality may have been achieved at the expense of surface water quality. As such, reduced atmospheric $\mathrm{S}$ emissions may have inadvertently contributed to increasing SP loadings to water bodies, a major cause of eutrophication and water-quality impairment globally.

Again, this study is preliminary in nature and does not provide definitive proof of Clean Air Act regulations diminishing water quality. This study does indicate further study is warranted. Other studies in the region have shown that the observed changes in SP loading are likely the result of a myriad of factors (Jarvie et al. 2017), and precipitation chemistry may simply be another confounding factor. Whether or not the higher $\mathrm{pH} /$ lower $\mathrm{SO}_{4}$ precipitation received by WLEB soils and fertilizers in recent years and into the future impacts the SP losses, it is imperative that scientists, resource managers, and policy makers quickly find and implement strategies to decrease SP loading through WLEB tributaries.

\section{REFERENCES}

Berger,T.W., S. Turtscher, P. Berger, and L. Lindebner. 2016. A slight recovery of soils from acid rain over the last three decades is not reflected in the macro nutrition of beech (Fagis sylvatica) at 97 forest stands of the Vienna Woods. Environmental Pollution 216:624-635.

Caldwell, A.C., E.C. Seim, and G.W. Rehm. 1969. Sulfur effects on the elemental composition of alfalfa (Medicago sativa L.) and corn (Zea mays L.). Agronomy Journal 61(4):632-634.

Evans, C.D., D.T. Monteith, and D.M. Cooper. 2005. Long-term increases in surface water dissolved organic carbon: Observations, possible causes and environmental impacts. Environmental Pollution 137:55-71.

Folster, J., and A. Wilander. 2002. Recovery from acidification in Swedish forest streams. Environmental Pollution 117:379-389.

Helvey, J.D., S.H. Kunkle, and D.R. DeWalle. 1982. Acid precipitation: A review. Journal of Soil and Water Conservation 37(3):143-148.

Jarvie, H.P., L.T. Johnson, A.N. Sharpley, D.R. Smith, D.B. Baker and T.W. Bruulsema. 2017. Increased soluble phosphorus loads to Lake Erie: Unintended consequences of conservation practices? Journal of Environmental Quality 46(2):123-132.

Jones, M.B., P.W. Lawler, and J.E. Ruckman. 1970. Differences in annual clover responses to phosphorus and sulfur. Agronomy Journal 62(4):439-442.

Joose, P.J., and D.B. Baker. 2011. Context for re-evaluating agricultural source phosphorus loadings to the Great Lakes. Canadian Journal of Soil Science 91:317-327.

Kahl, J.S., J.L. Stoddard, R. Haeuber, S.G. Paulsen, R. Birnbaum, F.A. Deviney, J.R. Webb, D.R. Dewalle, W. Sharpe, C.T. Driscoll, A.T. Herlihy, J.H. Kellogg, P.S. Murdoch, K. Roy, K.E. Webster, and N.S. Urquhart. 2004. Have US surface waters responded to the 1990 Clean Air Act Amendments? Environmental Science and Technology 38:484A-390A.

Karlsson, G.P., C. Akselsson, S. Hellsten, and P.E. Karlsson. 2011. Reduced European emissions of $\mathrm{S}$ and $\mathrm{N}$ - Effects on air concentrations, deposition and soil water chemistry in Swedish forests. Environmental Pollution 159:3571-3582.

King, K.W., M.R. Williams, and N.R. Fausey. 2015. Contributions of systematic tile drainage to watershed-scale phosphorus transport. Journal of Environmental Quality 44(2):486-494.

King, K.W., M.R. Williams, L.T. Johnson, D.R. Smith, G.A., LaBarge, and N.R. Fausey. 2017. Phosphorus availability in Western Lake Erie Basin drainage waters: Legacy evidence across 
spatial scales. Journal of Environmental Quality 46(2):466-469.

Kopacek, J., J. Hejzlar, J. Kana, S.A. Norton, and E. Stuchlik. 2015. Effects of acid deposition on inlake phosphorus availability: A lesson from lakes recovering from acidification. Environmental Science and Technology 49:2895-2903.

Lawrence, G.B., H.A. Simonin, B.P. Baldigo, K.M. Roy, and S.B. Capone. 2011. Changes in the chemistry of acidified Adirondack streams from the early 1980s to 2008. Environmental Pollution 159:2750-2758.

Monteith, D.T., J.L. Stoddard, C.D. Evans, H.A. deWit, M. Forsius, T. Hogasen, A. Wilander, B.L. Skjelvale, D.S. Jeffries, J. Vouremmaa, B. Keller, J. Kopacek, and J. Vesely. 2007. Dissolved organic carbon trends resulting from changes in atmospheric deposition chemistry. Nature 450:537-541.

Neal, C., S. Lofts, C.D. Evans, B. Reynolds, E. Tipping, and M. Neal. 2008. Increasing iron concentrations in UK upland waters. Aquatic Geochemistry 14(3):263-288.

Oulehle, F., and J. Hruska. 2009. Rising trends of dissolved organic matter in drinking-water reservoirs as a result of recovery from acidification in the Ore Mts., Czech Republic. Environmental Pollution 157:3433-3439.

Seaborn, J.B. 1982. A Canadian perspective on acid deposition. Journal of Soil and Water Conservation 37(2):67.

Smith, D.R., W. Francesconi, S.J. Livingston, and C. Huang. 2015a. Phosphorus losses from monitored fields with conservation practices in the Lake Erie Basin, USA. Ambio 44(Suppl. 2):S319-S331.

Smith, D.R., R.D. Harmel, M. Williams, R. Haney, and K.W. King. 2016. Managing acute phosphorus loss with fertilizer source and placement: Proof of concept.Agricultural and Environmental Letters 1(1).

Smith D.R., C. Huang, and R. Haney. 2017. Phosphorus fertilization, soil stratification and potential water quality impacts. Journal of Soil and Water Conservation In Press.

Smith, D.R., K.W. King, L. Johnson, W. Francesconi, P. Richards, D. Baker, and A.N. Sharpley. 2015b. Surface runoff and tile drainage transport of phosphorus in the Midwestern United States. Journal of Environmental Quality 44:495-502.

Smith, D.R., K.W. King, and M.R. Williams. 2015c. What is causing the harmful algal blooms in Lake
Erie? Journal of Soil and Water Conservation 70(2):27A-29A, doi:10.2489/jswc.70.2.27A.

Smith, D.R., R. Wilson, K.W. King, M. Zwonitzer, J.M. McGrath, R.D. Harmel, R. Haney, and L. Johnson. 2018. Lake Erie, phosphorus and microcystin: Is it really the farmer's fault? Journal of Soil and Water Conservation In Press.

Sopauskiene, D., and D. Jacineviciene. 2006. Changes in precipitation chemistry in Lithuania for 1981 2004. Journal of Environmental Monitoring 8:347-352.

Stevens, C.J., N.B.Dise, and D.J. Gowing. 2009. Regional trends in soil acidification and exchangeable metal concentrations in relation to acid deposition rates. Environmental Pollution 157:313-319.

Stoddard, J.L., J.Van Sickle, A.T. Herlihy, J. Brahney, S. Paulsen, D.V. Peck, R. Mitchell, and A.I. Pollard. 2016. Continental-scale increase in lake and stream phosphorus: Are oligotrophic systems disappearing in the United States? Environmental Science and Technology 50(7):3409-3415, doi: 10.1021/acs.est.5b05950.

Strock, K.E., S.J. Nelson, J.S. Kahl, J.E. Saros, and W.H. McDowell. 2014. Decadal trends reveal recent acceleration in the rate of recovery from acidification in the Northeastern U.S. Environmental Science and Technology 48:4681-4689.

Tipping,E.,J.A.B.Bass, D. Hardie, E.Y.Haworth, M.A. Hurley, and G. Wills. 2002. Biological response to the reversal of acidification in surface waters of the English Lake District. Environmental Pollution 116:137-146.

Vanguelova, E.I., S. Benham, R. Pitman, A.J. Moffat, M. Broadmeadow, T. Nisbet, D. Durrant, N. Barsoum, M. Wilkinson, F. Bochereau, T. Hutchings, S. Broadmeadow, P. Crow, P. Taylor, and T. Durrant Houston. 2010. Chemical fluxes in time through forest ecosystems in the UK - Soil response to pollution recovery. Environmental Pollution 158:1857-1869.

van Kleef, H.H., E. Brouwer, R.S.E.W. Leuben, H. van Dam,A. deVries-Brock, G. can derVelde, and H. Esselink. 2010. Effects of reduced nitrogen and sulphur deposition on the water chemistry of moorland pools. Environmental Pollution 158:2679-2685.

Williams, M.R., K.W. King, D.B. Baker, L.T. Johnson, D.R. Smith, and N.R. Fausey. 2017. Hydrologic and biogeochemical controls on phosphorus export from Western Lake Erie tributaries. Journal of Great Lakes Research 46(6):1403-1411. 